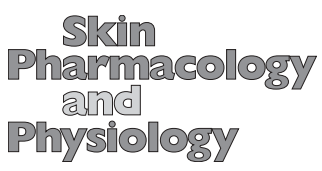

\title{
Report of the Second Meeting of the International Society of Skin Pharmacology and Physiology (ISP)
}

The 2nd meeting of the International Society of Skin Pharmacology and Physiology (ISP) was held from the 5 th to the 7 th of November 2006 in Rome. Topics such as barrier function, skin irritation, biology of the stratum corneum, skin penetration, pharmacology and physiology, textiles and the skin were discussed by the participants from 13 different countries. The best presentations were accredited with an award from the ISP and will be published in one of the next issues of our journal.

We would like to express our most grateful thanks to Joachim Fluhr, University of Jena (Germany), and Enzo Beradesca, University of Rome (Italy), for the exceptional scientific preparation of the meeting. Both the excellent scientific program and smooth organization under their direction contributed to the success of the meeting and the highly interesting, intensive discussions.

The next Annual Meeting of the ISP is planned as a joint meeting, following the Gordon Conference 'Barrier Function of Mammalian Skin' in August 2007, in the United States. This meeting will be organized together with the GRC, FDA and NIH.

At the meeting of the ISP, a new board consisting of the following members was elected: Hervez Bachelez
(France); Eva Benfeld (Denmark); Enzo Beradesca (Italy); Joachim Fluhr (Germany); Richard Guy (UK); Walter Holleran (USA); Yo Kawakubo (Japan); Jürgen Lademann (Germany); Reinhard Neubert (Germany); Michael Roberts (Australia); Christian Surber (Switzerland).

The ISP will work on bringing together scientists from different areas of skin pharmacology and skin physiology in order to create an umbrella for broadening the scientific network in this area.

For further information concerning the program and the activities of the ISP, please visit the following website: http://www.isp-society.org/meetings.html.

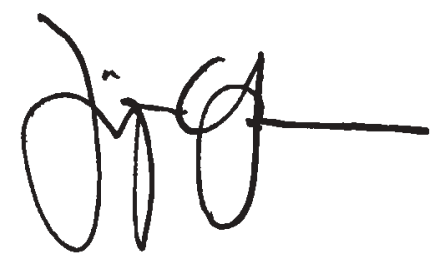

Jürgen Lademann President of the ISP

\section{KARGER}

Fax +41 613061234 E-Mail karger@karger.ch www.karger.com (c) 2007 S. Karger AG, Basel

1660-5527/07/0201-0001\$23.50/0 